
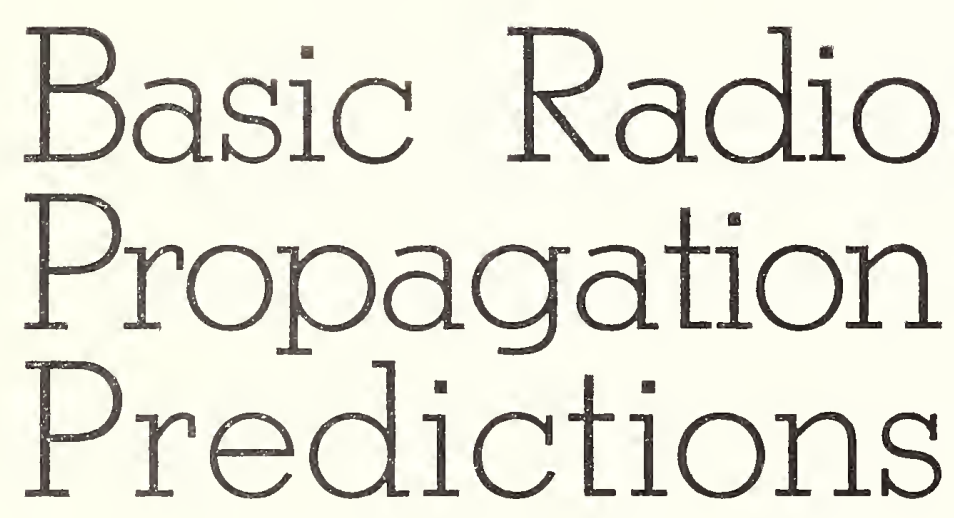

FOR JULY 1962

Three Months in Advance 


\section{The Central Radio Propagation Laboratory}

The propagation of radio waves over long distances depends on their reflection from the ionosphere, the electrically conducting layel's in the earth"s upper atmosphere. The characteristics of these layers are continually changing. For regular and reliable communication, it is therefore necessary to collect and analyze ionospheric data from stations all over the world in order that predictions of usable frequencies between any two places at any hour can be made. During the war, the United States Joint Communications Board set up the Interservice Radio Propagation Laboratory at the National Bureau of Standards to centralize ionospheric work and predictions for the Armed Forces of the United States.

On May 1, 1946, this activity returned to peacetime status as the Central Radio Propagation Laboratory of the National Bureau of Standardis. Designed to act as a permanent centralizing agency for propagation predictions and studies, analogous in the field of radio to the reports of the Weather Bureau in the field of meteorology, the Central Radio Propagation Laboratory was established in cooperation with the many government agencies vitally concerned with communication and radio propagation problems. These agencies are represented on an Interdepartmental Council on Radio Propagation and Standards, which assists in furthering the work of the Laboratory; inclurder are the Departments of State, Army, Navy, and Air Force, United States Information Agency, United S'ates Coast Guard, Civil Aeronauties Administration, and Federal Communications Commission. Observers have been lesignated by the Air Navigation Development Board, Interdepartment Radio Advisory Committee, United States Coast and Geodetic Survey, and United States Weather Bureau. The Council works in cooperation with a Technical Advisory Committee appointed by the Institute of Radio Engineers at the request of the Director, National Bureau of Standards.

The Central Radio Propagation Laboratory receives and analyzes data from approximately 120 stations located throughoxt the world, including 8 domestic and 17 overseas stations which are operated either directly oi under contract by tha National Bureau of Standards. Ionospherie data and predictions are disseminated to the Armed Fores, commercial usel's, scientists, and laboratories. The basic ionospheric research of the Laboratory includes theoretical and experimental studies of maximum usable frequencies, ionospheric absorption, longtime variations of ladio propagation characteristics, the effects of the sun on radio propagation, and the relation between radio disturbance and geomagnetic variation. In the microwave field, the Laboratory is investigating the relation between radio propagation and weather phenomena, as well as methods by which predictions can be made and radio communications improved in this portion of the radiofrequency spectrum. Another phase of the Laboratory's work is the development and maintenance of standards and methods of measurement of many basic electrical quantities throughout the entire frequency spectrum.

\section{Basic Radio Propagation Predictions}

The CRPL Series D, Basic Radio Propagation Predictions, is issued monthly as an aid in the determination of the best sky-wave frequencies over any path at any time of day for average conditions for the month of prediction, 3 months in advance. Charts of extraordinary-wave eritical frequency for the $F 2$ layer, of maximum usable frequency for a transmission distance of $4,000 \mathrm{~km}$, and of percentage of time occurence for transmission by sporadic $E$ in excess of $15 \mathrm{Mc}$, for a distance of $2,000 \mathrm{~km}$, ale inclucled.

Beginning" with the January 1960 issue (CRPL-D185) the CRPL-R series, "Basic Radio Iropagation Predictions," is available on a purchase basis from the Superintendent of Documents, U. S. Government Printing Office, Washington 25, D. C., on the following terms:

$$
\begin{aligned}
& \text { Single copy .......................................................................... } 15 \text { cents } \\
& \text { Annual subscription (12 issues) .......................................... } \$ 1.50
\end{aligned}
$$

( To foreign countries, $\$ 2.00$ )

The rules of the Superintendent of Doeuments require that remittances be made in advance either by coupons sold in sets of $20 \mathrm{for} \$ 1$ and good until used, or by check or money order payable to the Superintendent of Documents. Currency, if used, is at sender's risk. Postage stamps, foreign money, and defaced or smooth coins are not acceptable. Remittances from foreign countries should be by international money order payable to the Superintendent of Documents or by clraft on a United States bank.

Address subscriptions, remittances, and all inquiries relating thereto, to the Superintendent of Documents, U. S. Government Printing Oftice, Washington 25, D. C.

The printing of this publication has been approved by the Director of the Bureau of the Budget, June 19 , 1961. 
U. S. DEPARTMENT OF COMMERCE

Luther H. Hodges, Secretary

NATIONAL BUREAU OF STANDARDS

A. V. Astin, Director

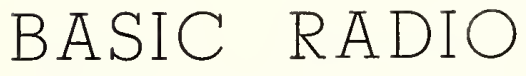

FOR JULY 1962

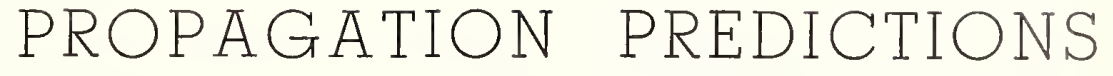

THREE MONTHS IN ADVANCE

\section{Introduction}

The CRPL-D series, "Basic Radio Propagation Predictions," issued by the National Bureau of Standards, contains contour charts of monthly median F2-zero-MUF and F2-4000-MUF for each of four zones, W, I (Afro-European), E, I (Pacific), (figs. 1 to 8); a worldwide contour chart of monthly median E-2000-MUF (fig. 9); a contour chart of median $f E$ s (fig. 10); and a chart showing percentage of time occurrence for Es-2000-MUF in excess of $15 \mathrm{Mc}$ (fig. 11). Local time used for North Pole: $75^{\circ} \mathrm{W}$; for South Pole: $105^{\circ} \mathrm{E}$.

Methods for using these charts are given in Circular 465 of the National Bureau of Standards, entitled "Instructions for the Use of Basic Radio Propagation Predictions," and available from the Superintendent of Documents, U. S. Government Printing Office, Washington 25, D. C., price 30 cents (to foreign countries, 40 cents). Procedures described in this manual should be modified to take into account the separate contour charts for the two I zones. Zone boundaries are the same as shown in figure 1 of Circular 465.

Requests for the manual of instructions and for the basic predictions from members of the Navy or Air Force should be sent to the proper service address as follows. For the Navy: The Director, Naval Communications. For the Air Force: Directorate Telecommunications, Department of the Air Force, Washington 25, D. C., Attention: AFOAC-FC.

Following figure 11 of each issue, sets of auxiliary figures (nos. 1, 2, 11, 12 of NBS Circular 465) or forms CRPL-AF and $\mathrm{AH}$ are given in rotation, two in each issue of CRPL Series D. They are necessary or useful for the preparation of tables and graphs of MUF and FOT (OWF), as explained in NBS Circular 465.

The charts in this issue were constructed from data through January 1962, together with the smoothed 12-month running-average Zïrich sunspot number 34, centered on July 1962 . The mean number for the year 1961 was 54.

Information concerning the theory of radio-wave propagation, measurement technics, structure of the ionosphere, ionospheric variations, prediction methods, absorption, field intensity, radio noise, lowest required radiated power, and lowest useful high frequency is given in Circular 462 of the National Bureau of Standards, "Ionospheric Radio Propagation." This circular is available from the Superintendent of Documents, price $\$ 1.25$ (to foreign countries, $\$ 1.65$ ). Additional information about radio noise may be found in NBS Circular 557, "Worldwide and Radio Noise Levels Expected in the Frequency Band 10 Kilocycles to 100 Megacycles," also available from the Superintendent of Documents, price 30 cents (to foreign countries, 40 cents) and in C.C.I.R. Report No. 65, "Revision of Atmospheric Radio Noise Data," International Telecommunication Union, Geneva, 1957. 
NORTH

LATITUDE

SOUTH

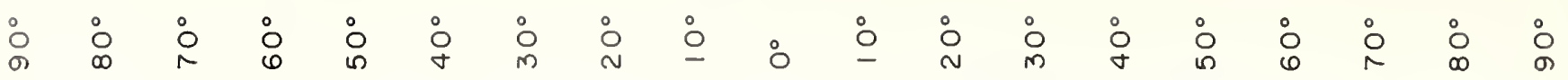

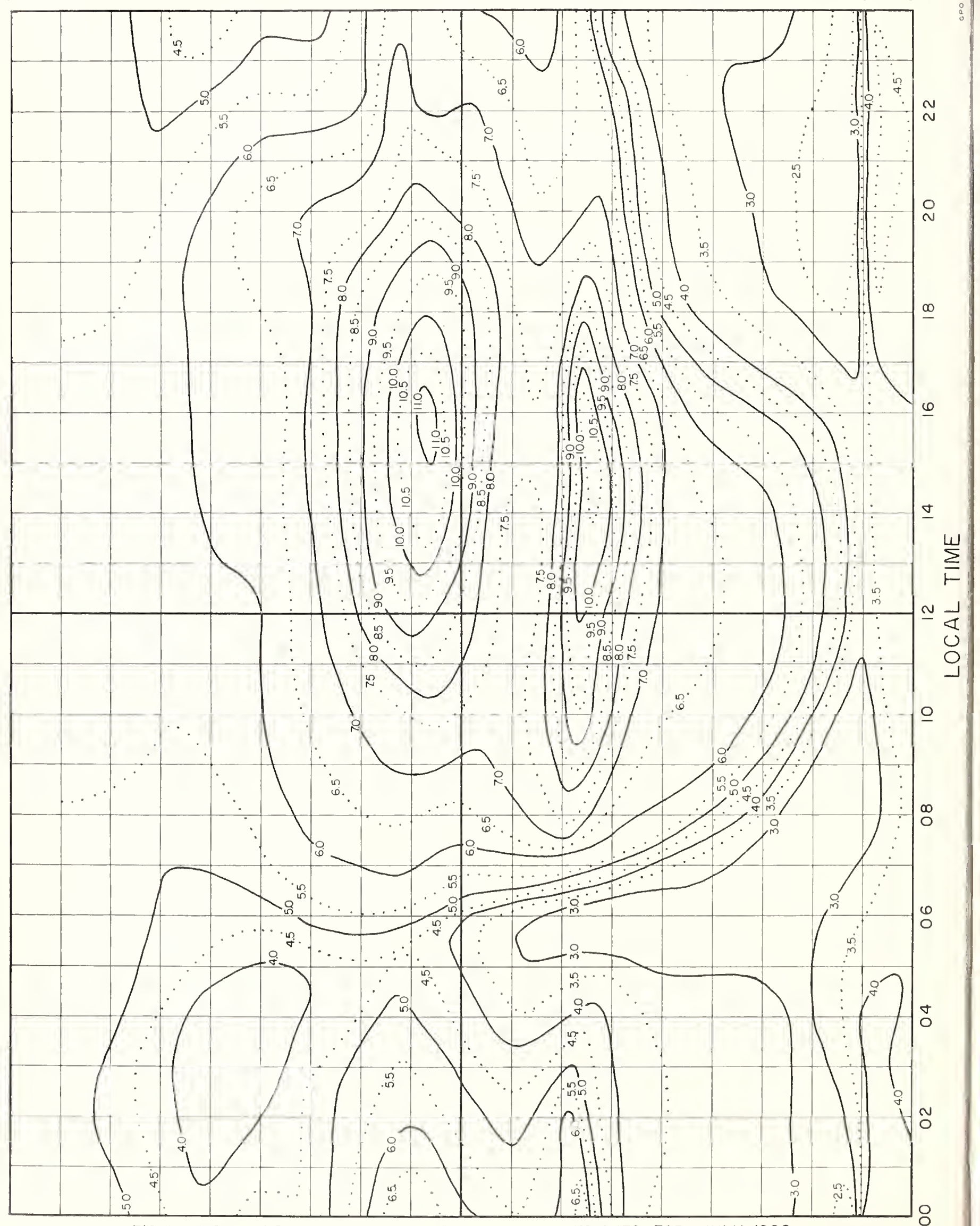


NORTH

LATITUDE

SOUTH

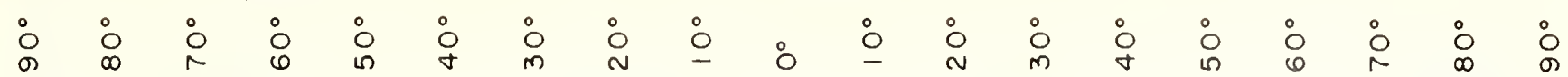

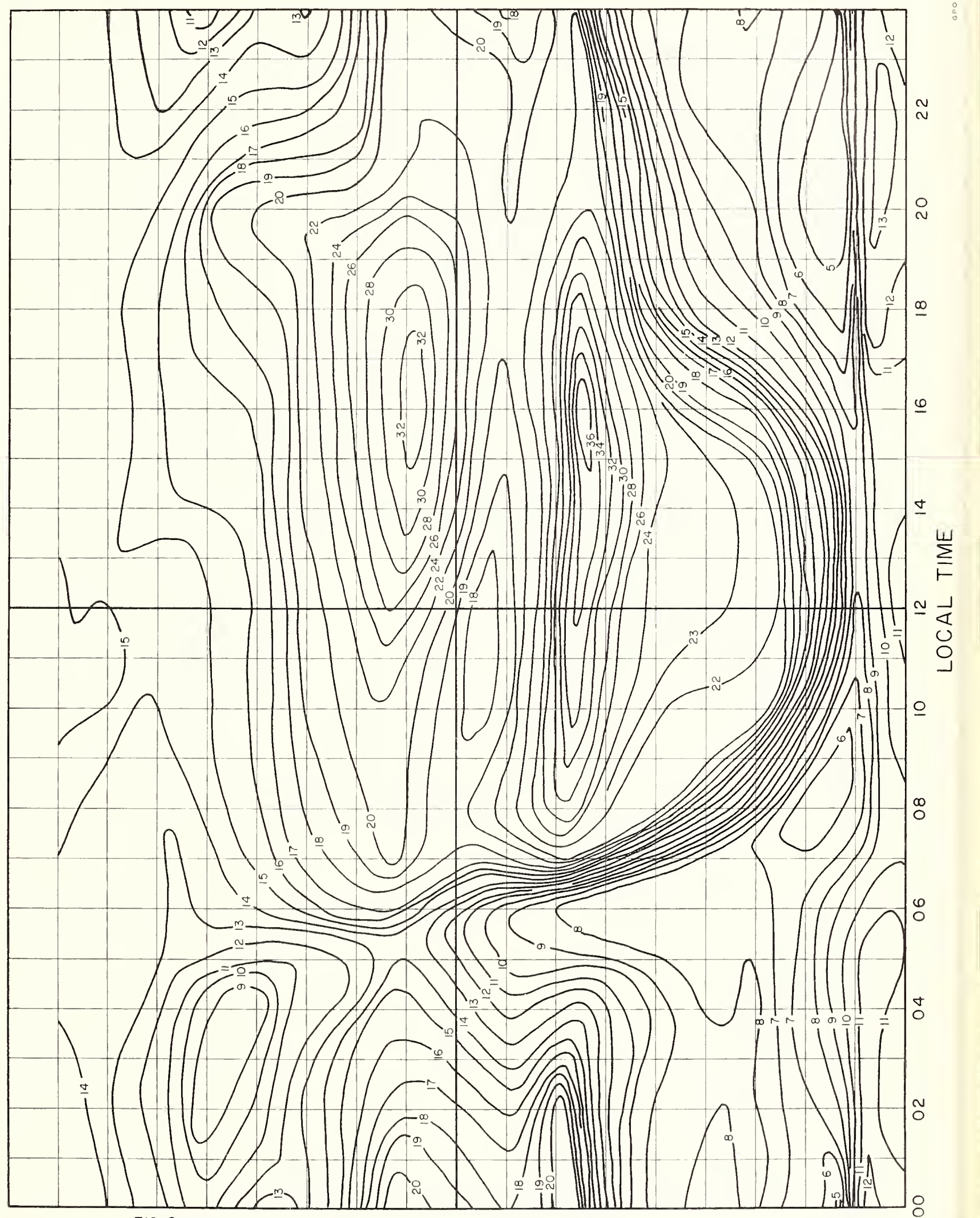

FIG. 2. MEDIAN F2-4000-MUF, IN Mc, W ZONE, PREDICTED FOR JULY 1962 


\section{NORTH \\ LATITUDE}

SOUTH

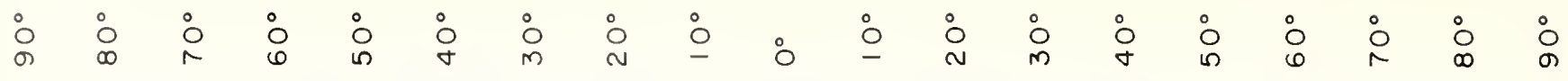

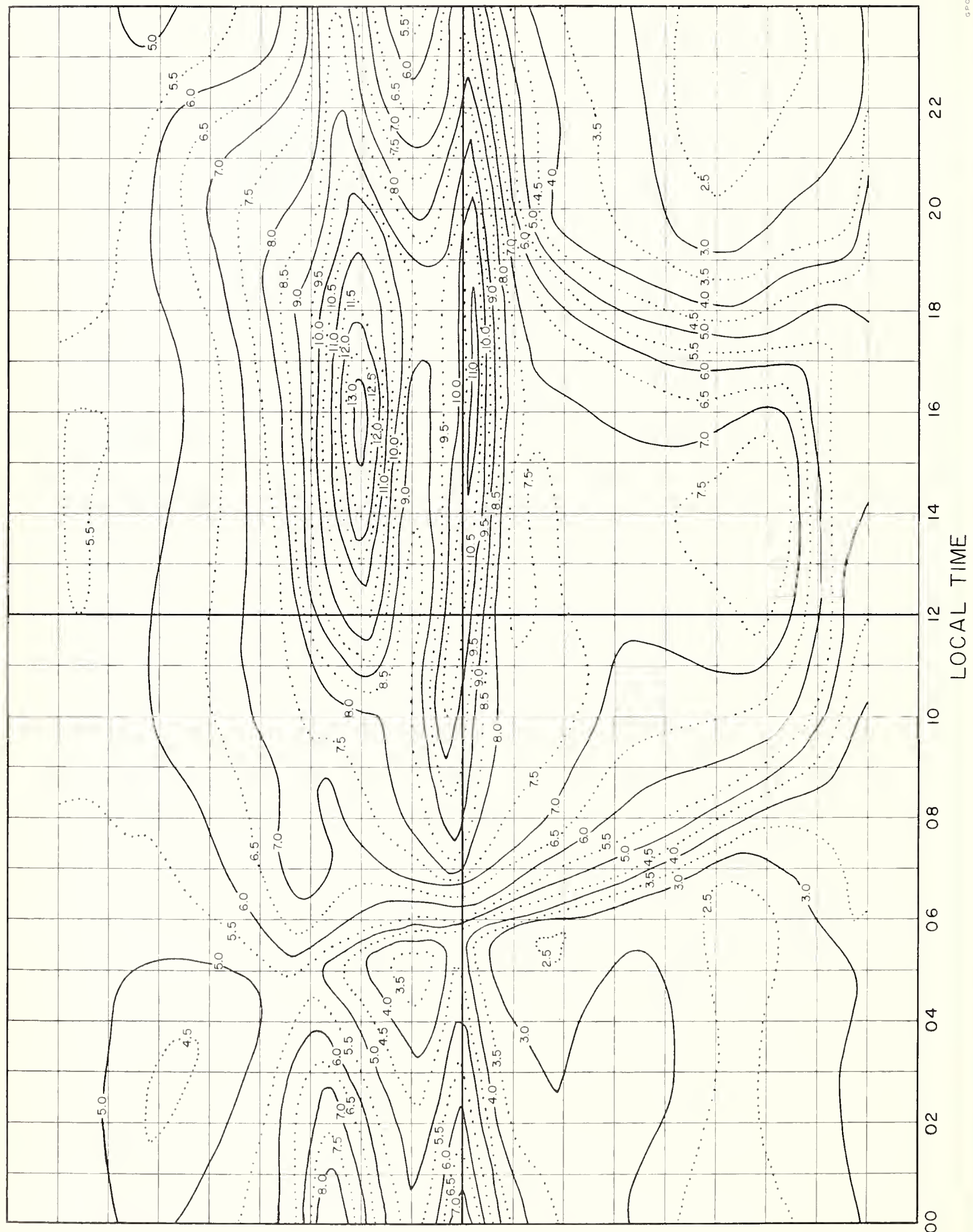

FIG.3. MEDIAN F2-ZERO-MUF, IN MC, I ZONE (AFRO-EUROPEAN), PREDICTED FOR JULY 1962 


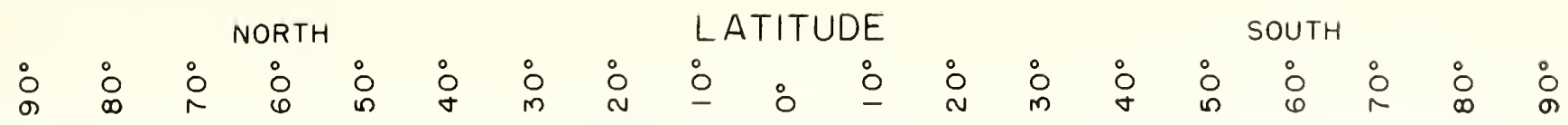

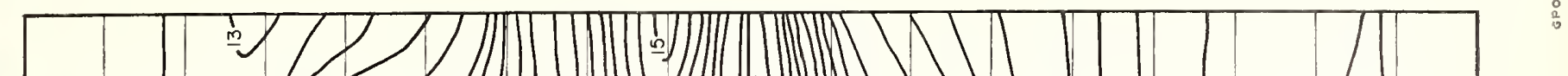

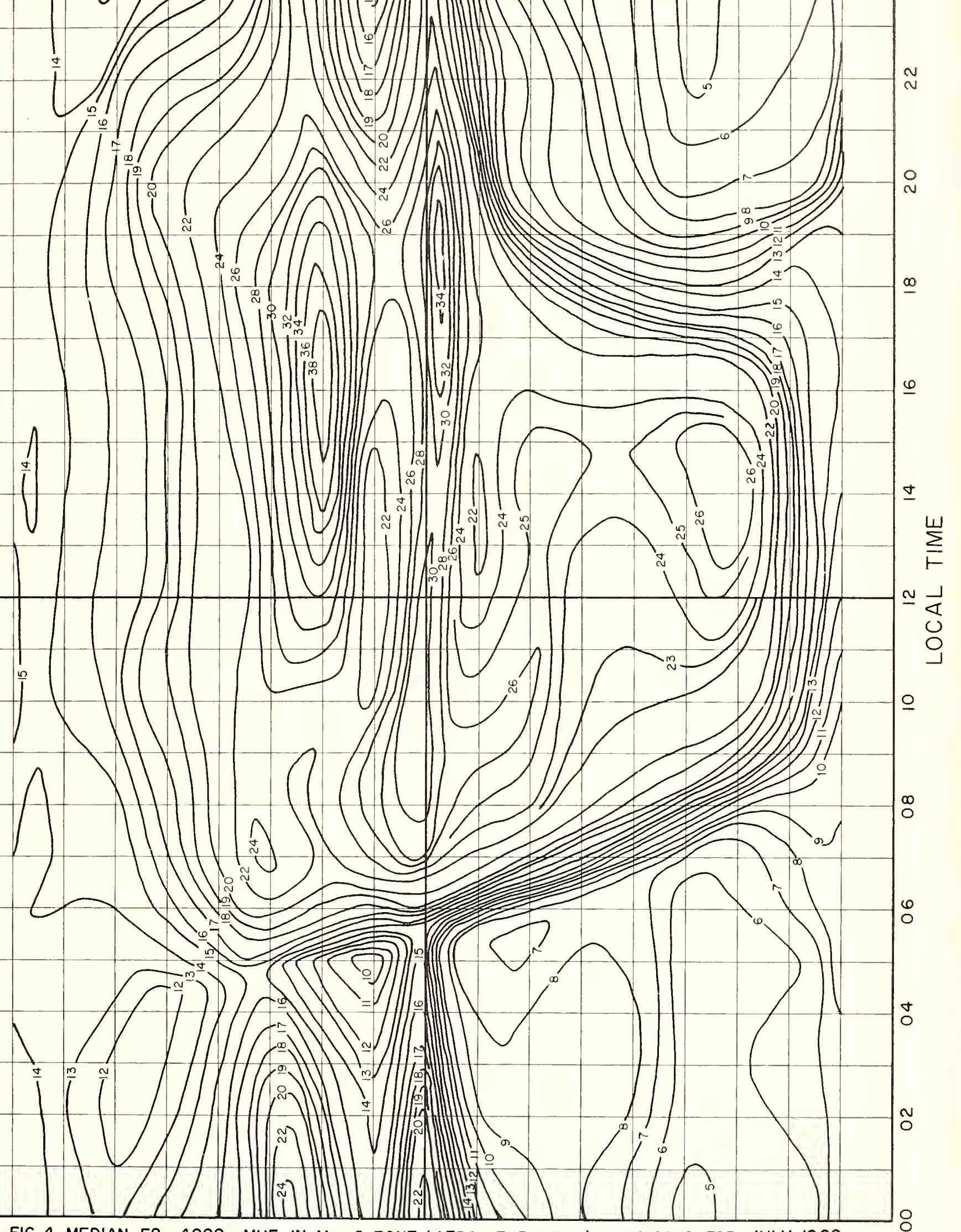

FIG. 4. MEDIAN F2-4000-MUF, IN MC, I ZONE (AFRO-EUROPEAN), PREDICTED FOR JULY 1962 


\section{NORTH LATITUDE SOUTH}

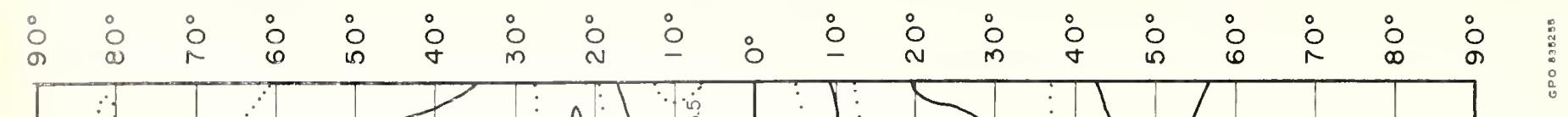
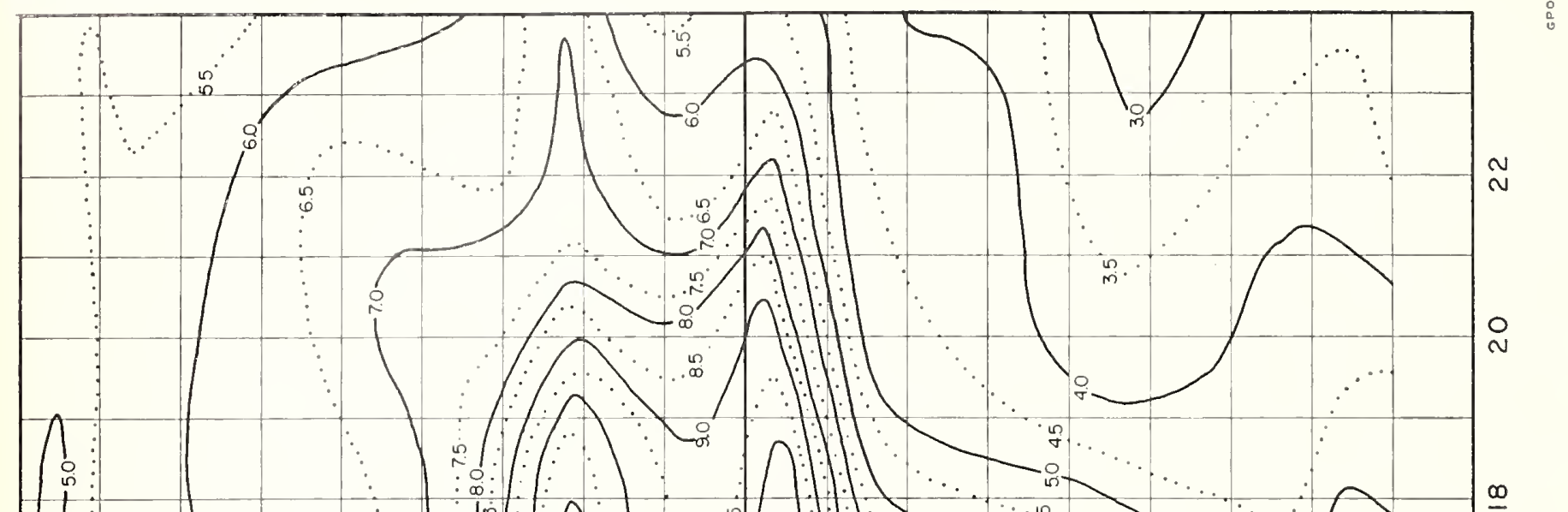

U
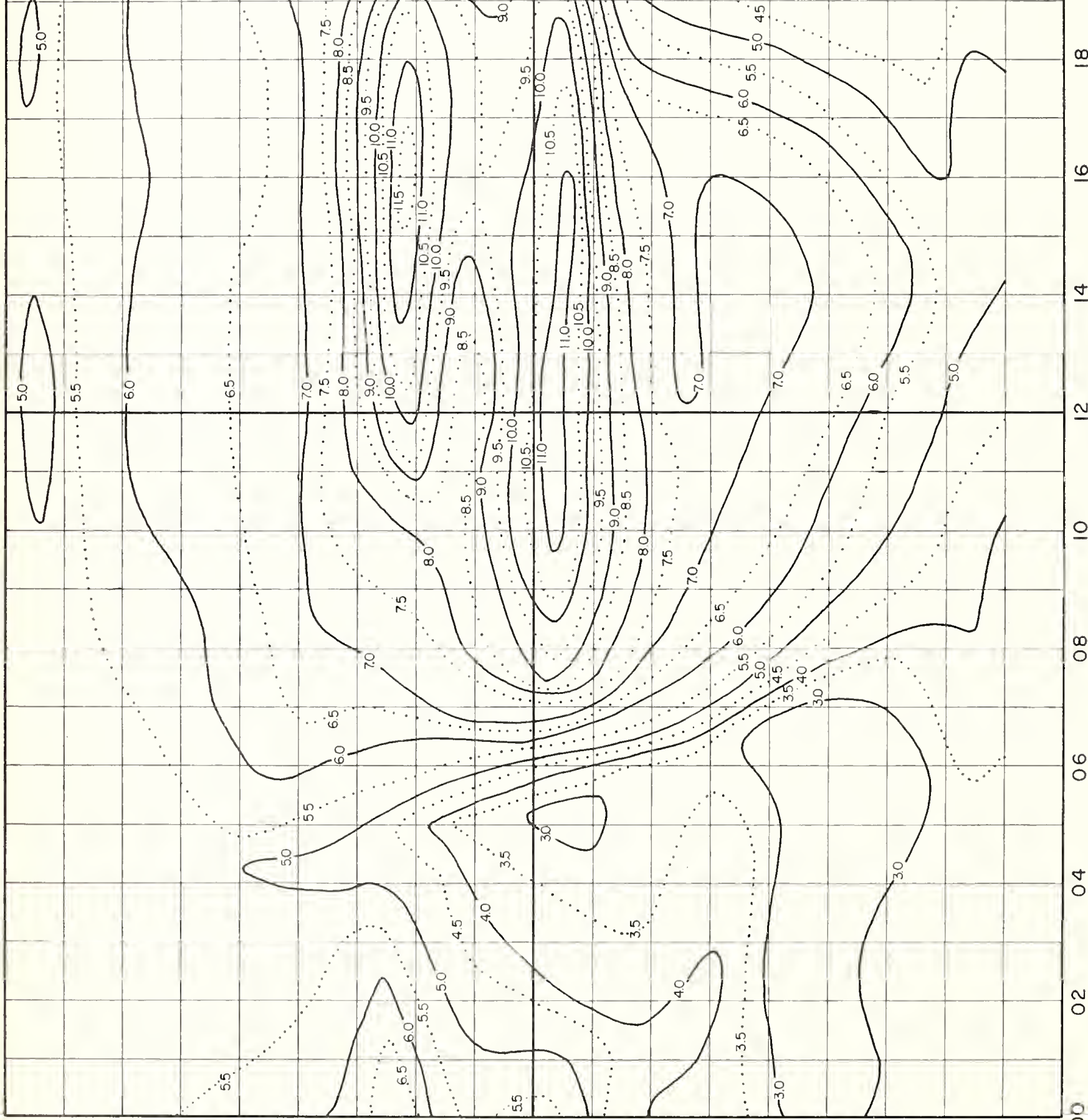

FIG. 5. MEDIAN F2 - ZERO - MUF, IN MC, E ZONE, PREDICTED FOR JULY 1962 


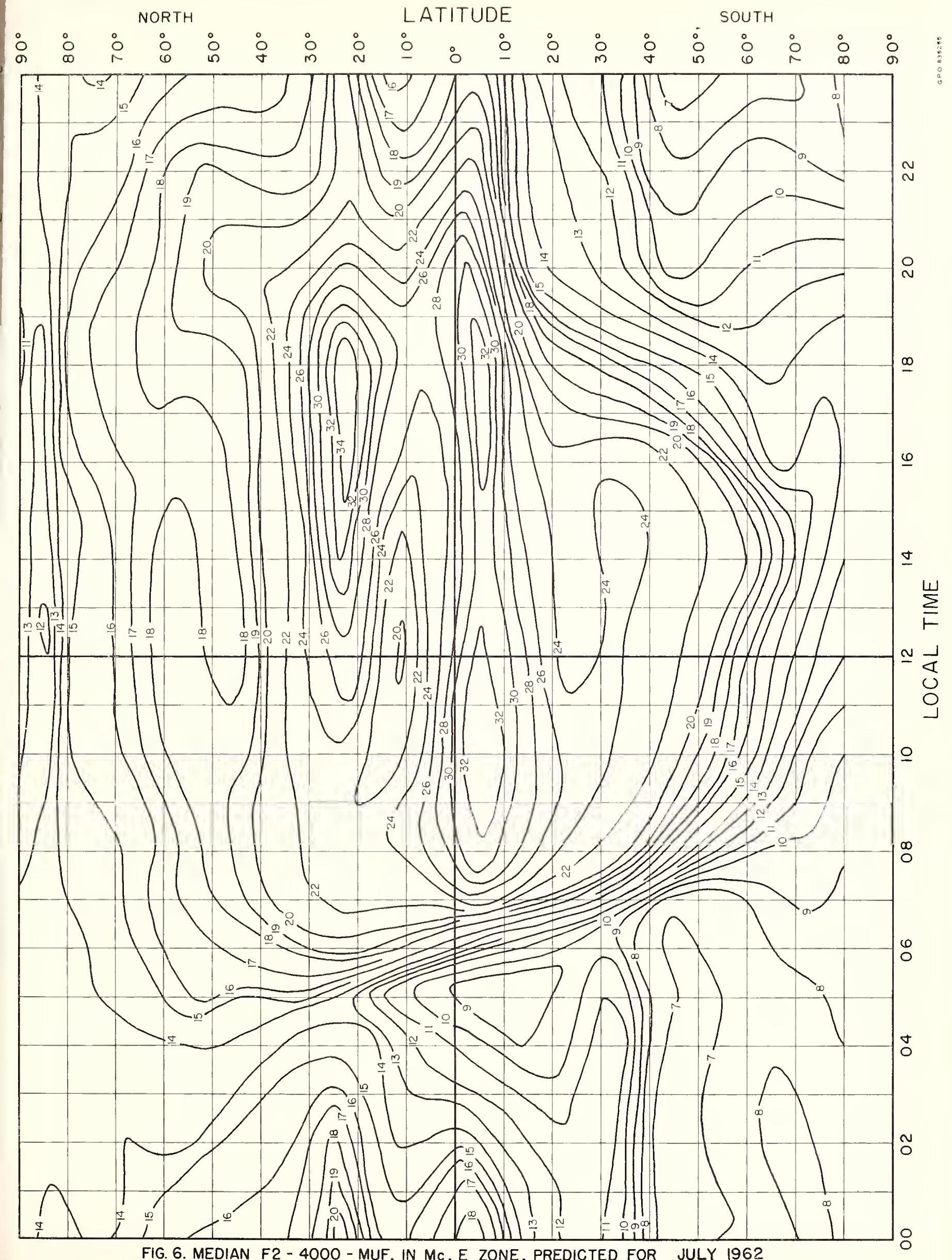




\section{NORTH \\ LATITUDE}

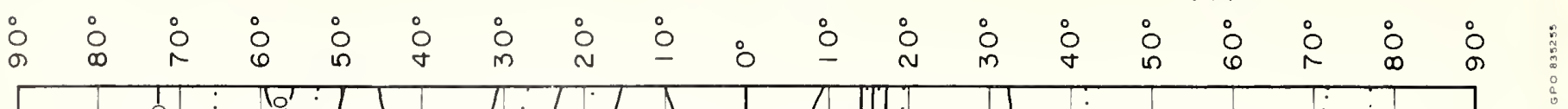

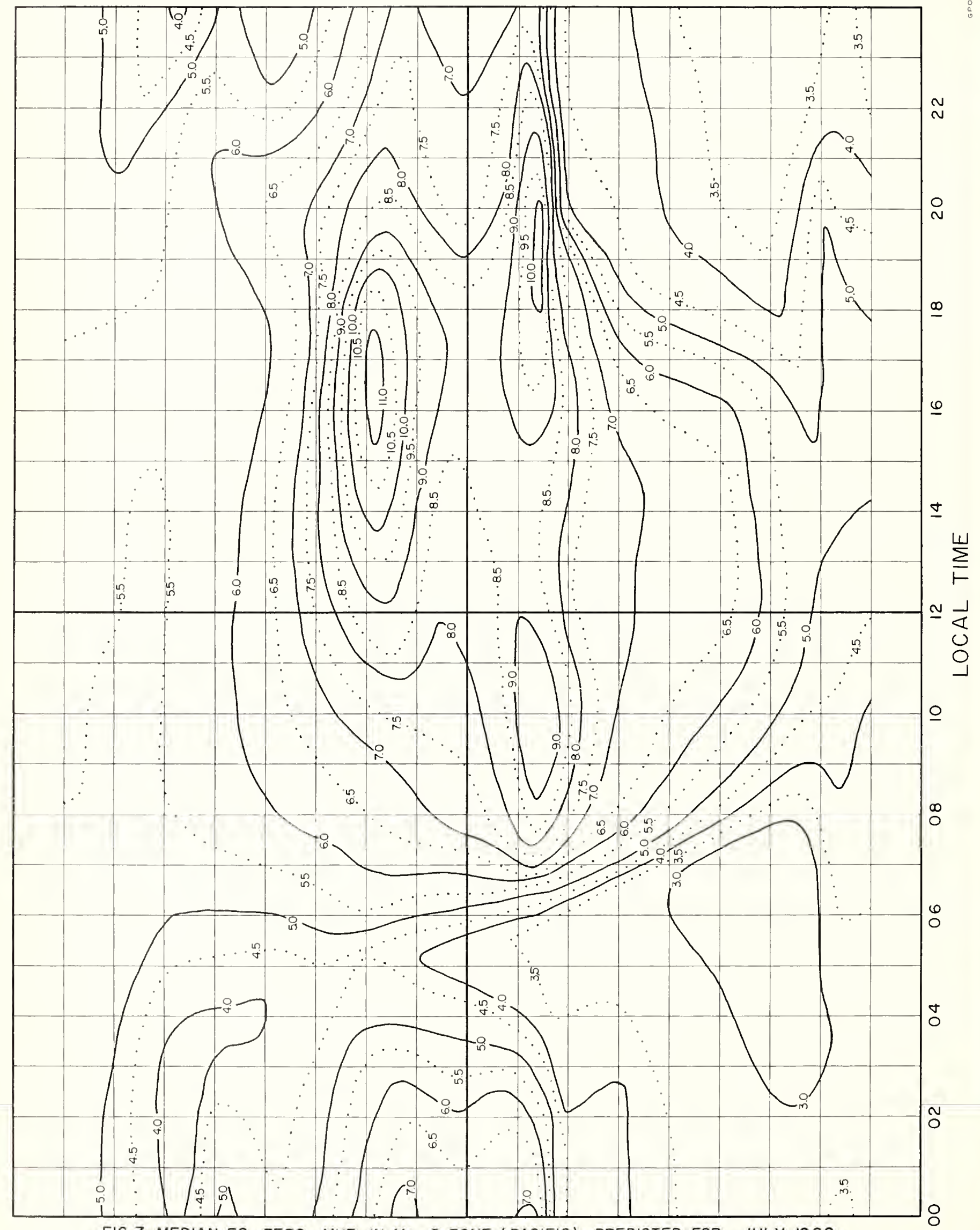

FIG. 7. MEDIAN F2 - ZERO - MUF, IN MC, I ZONE (PACIFIC), PREDICTED FOR JULY 1962 
NORTH LATITUDE SOUTH

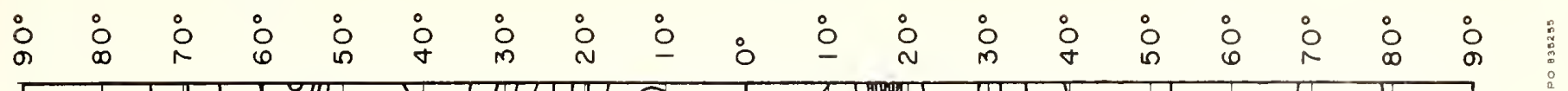

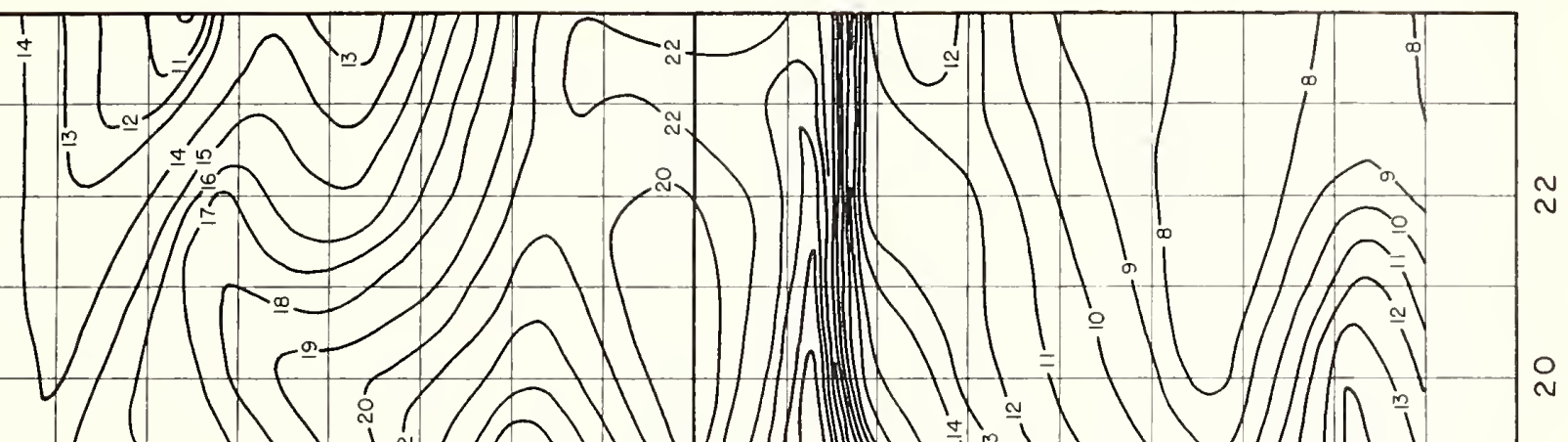

(
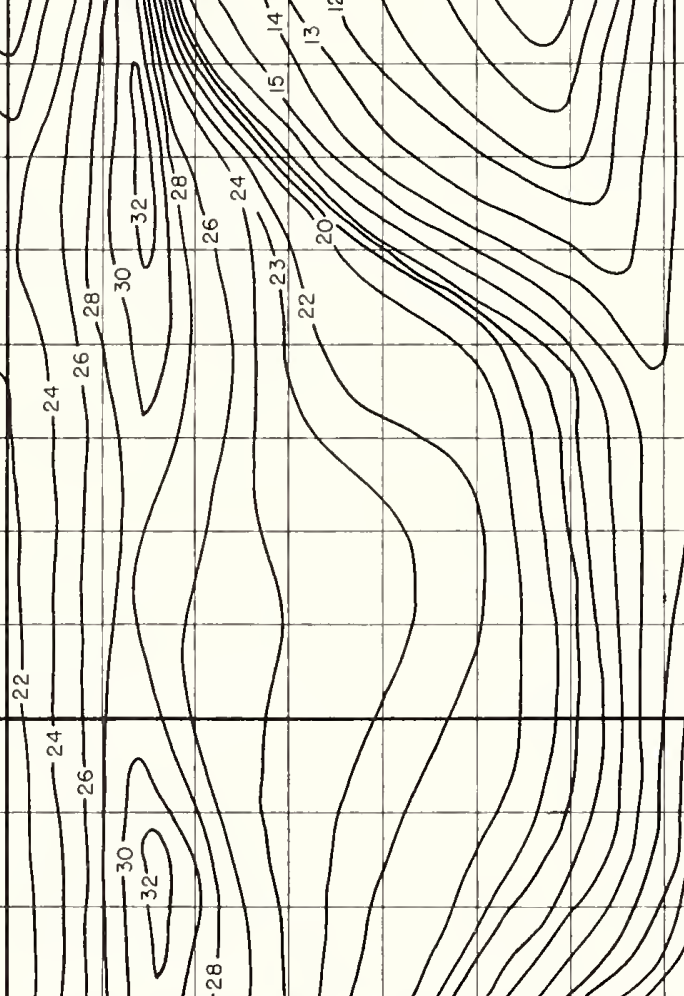

$m$
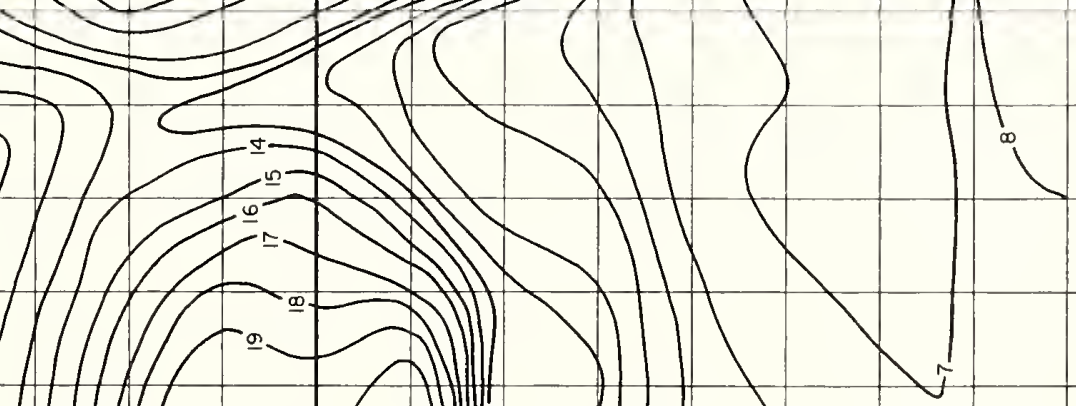


\section{NORTH LATITUDE SOUTH}

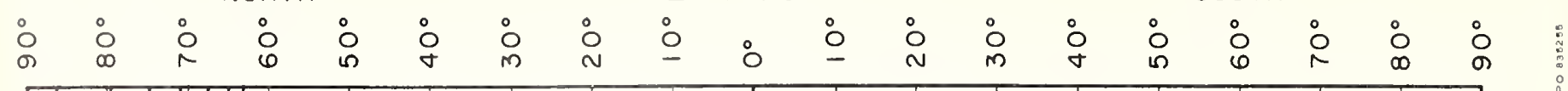

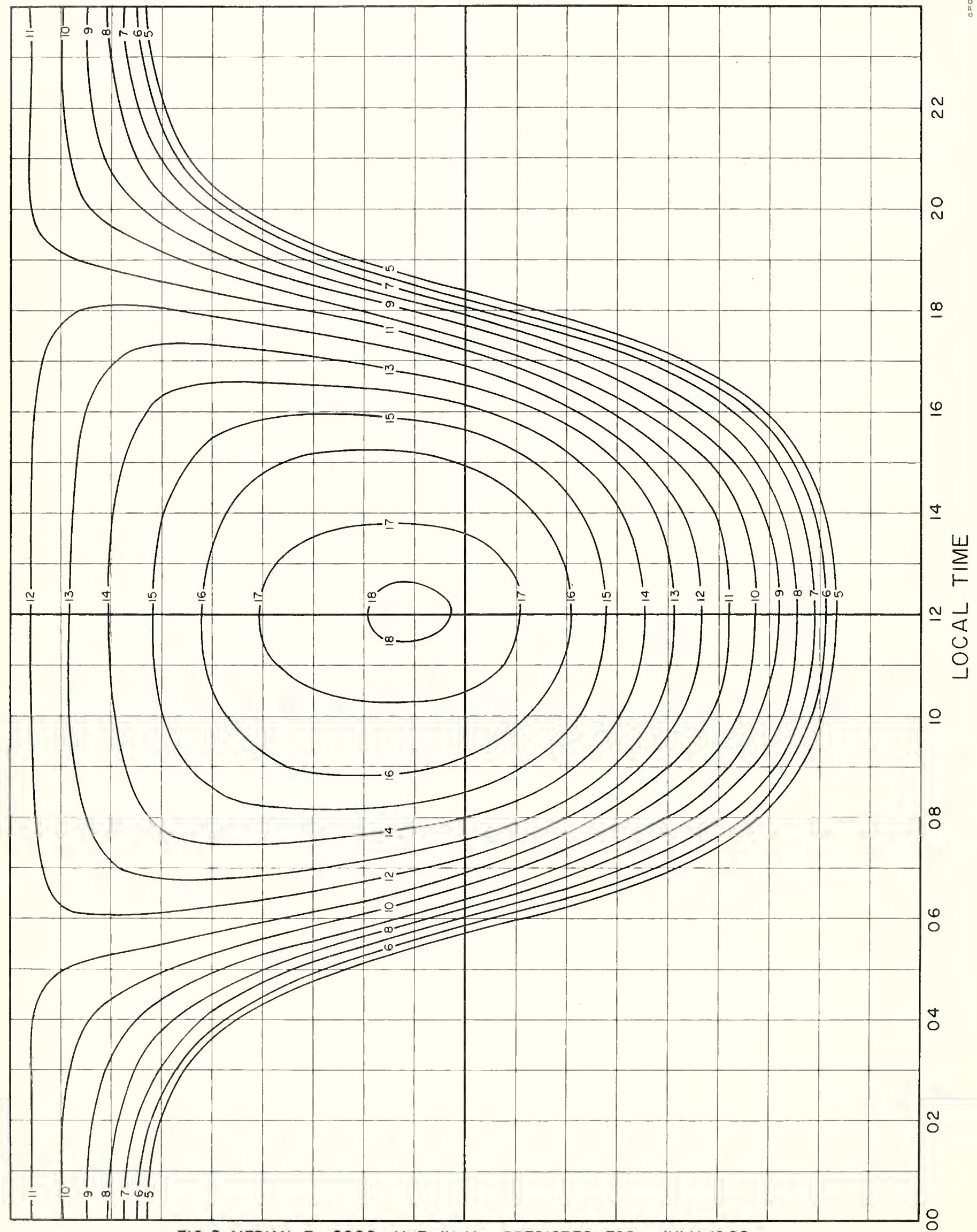


$\begin{array}{lll}\text { NORTH } & \text { LATITUDE } & \text { SOUTH }\end{array}$

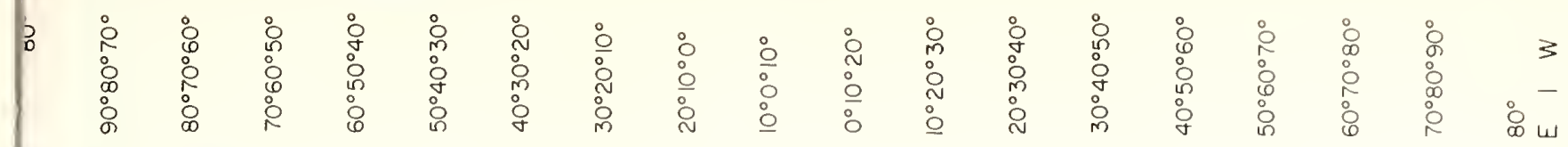
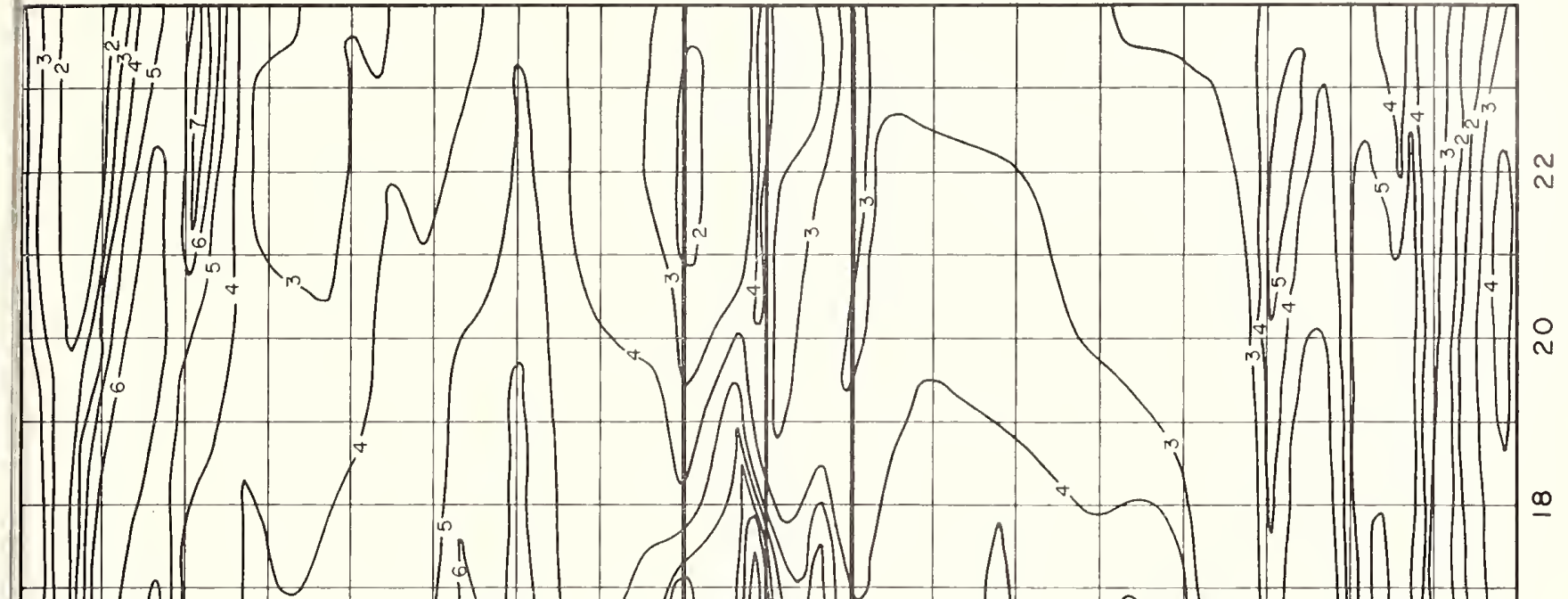

(6)

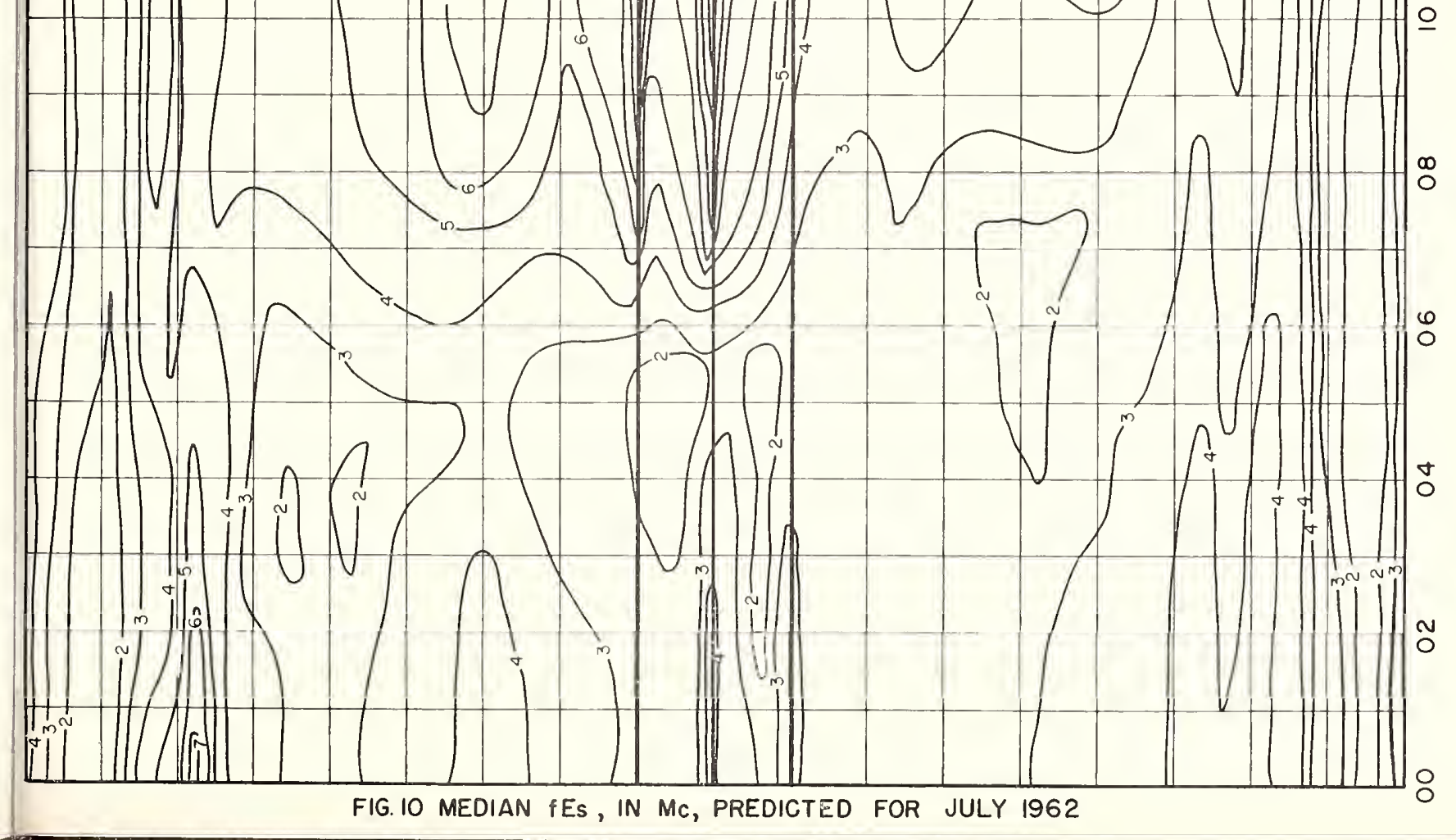


SOUTH

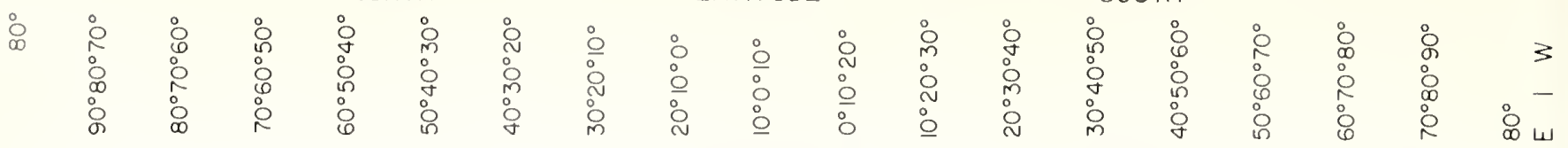

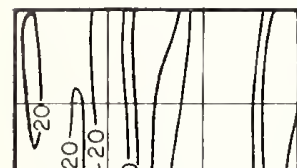

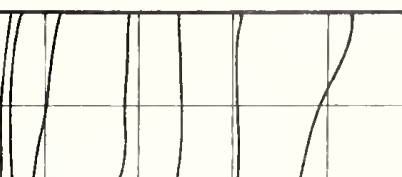

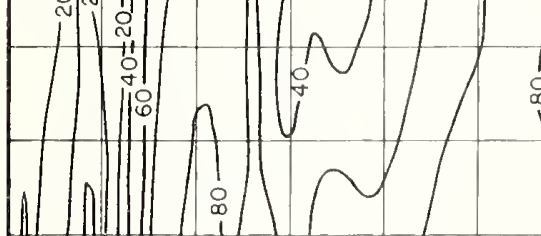

H 1 (I)

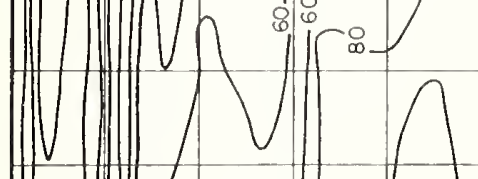

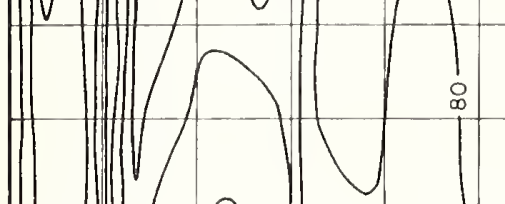

(I)

H $i^{i}$

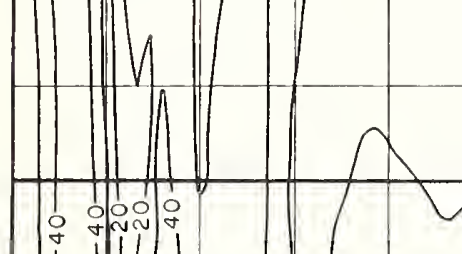

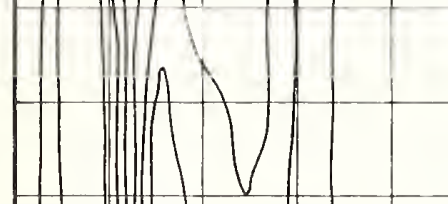
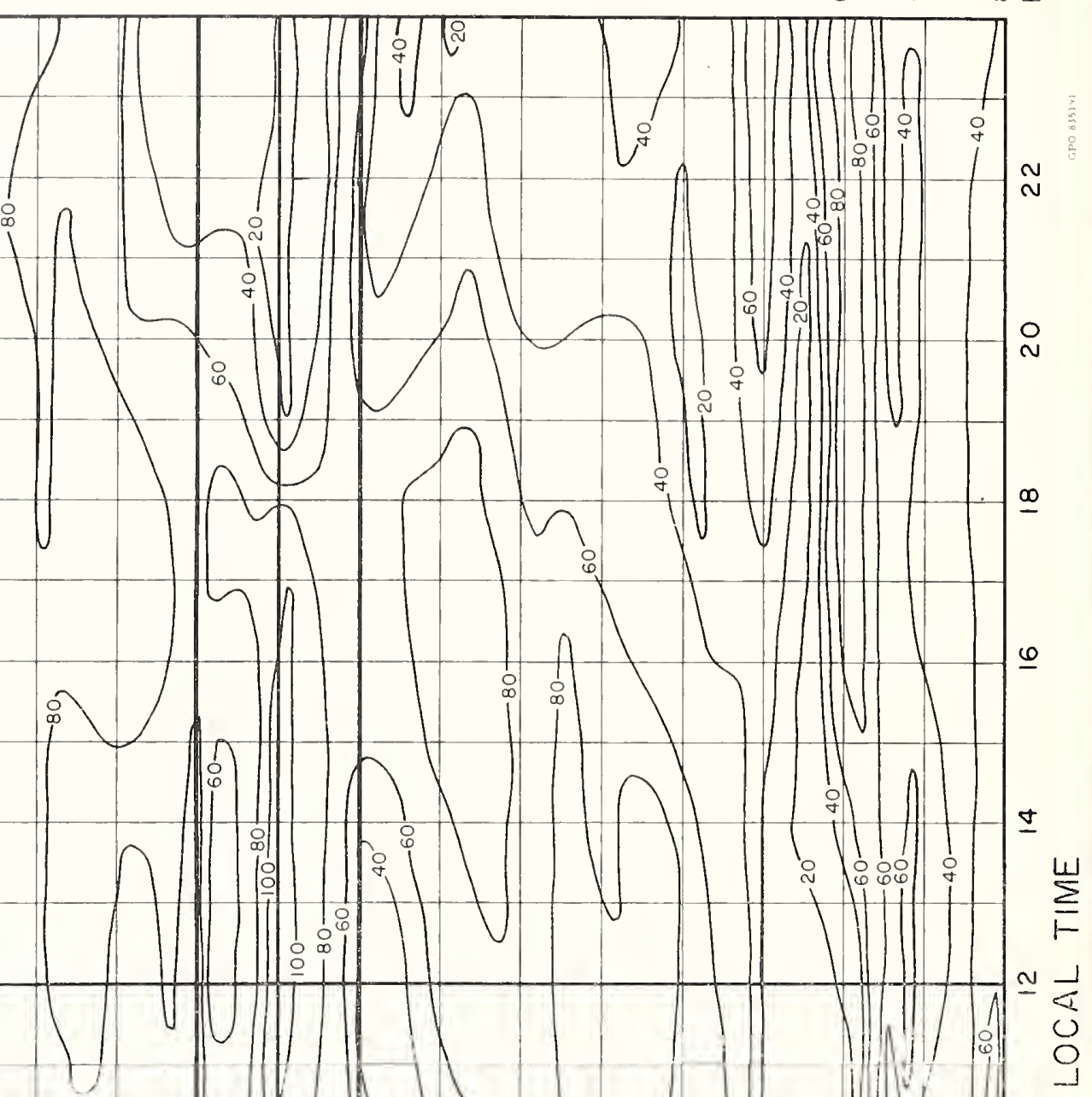

ะั1

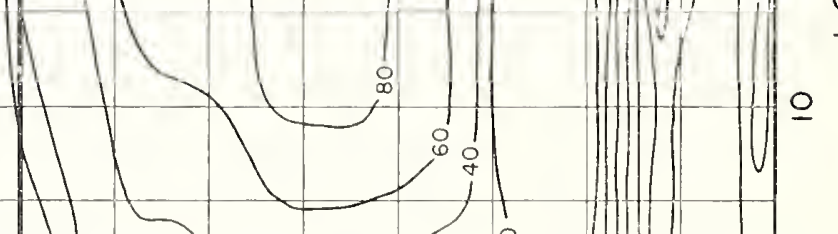

$\infty$
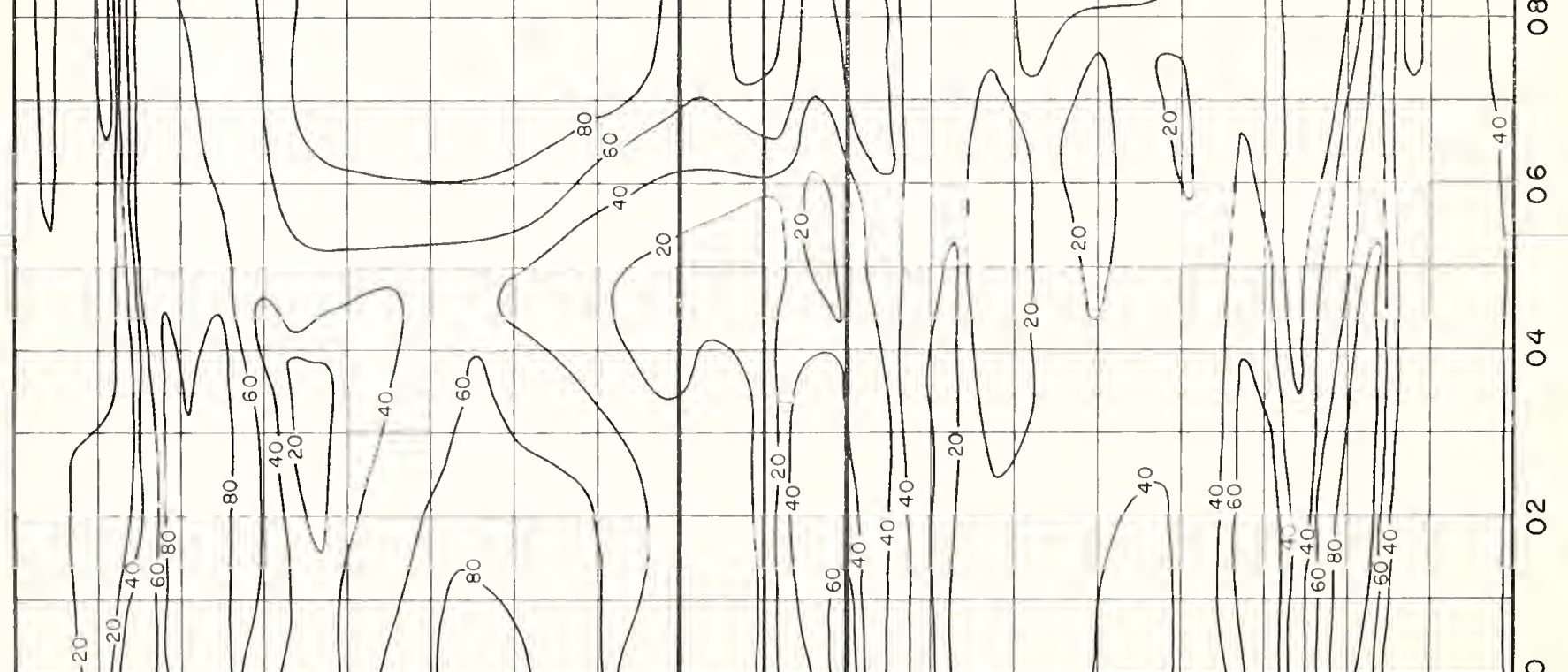

10
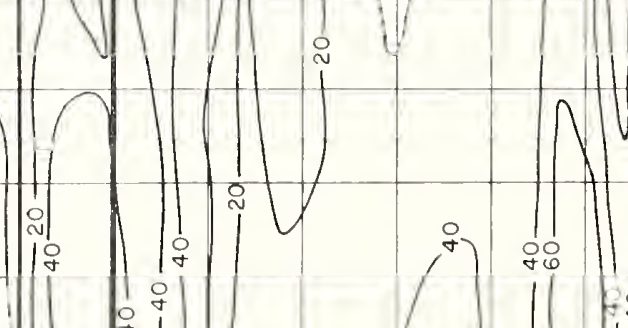

n

11 年 


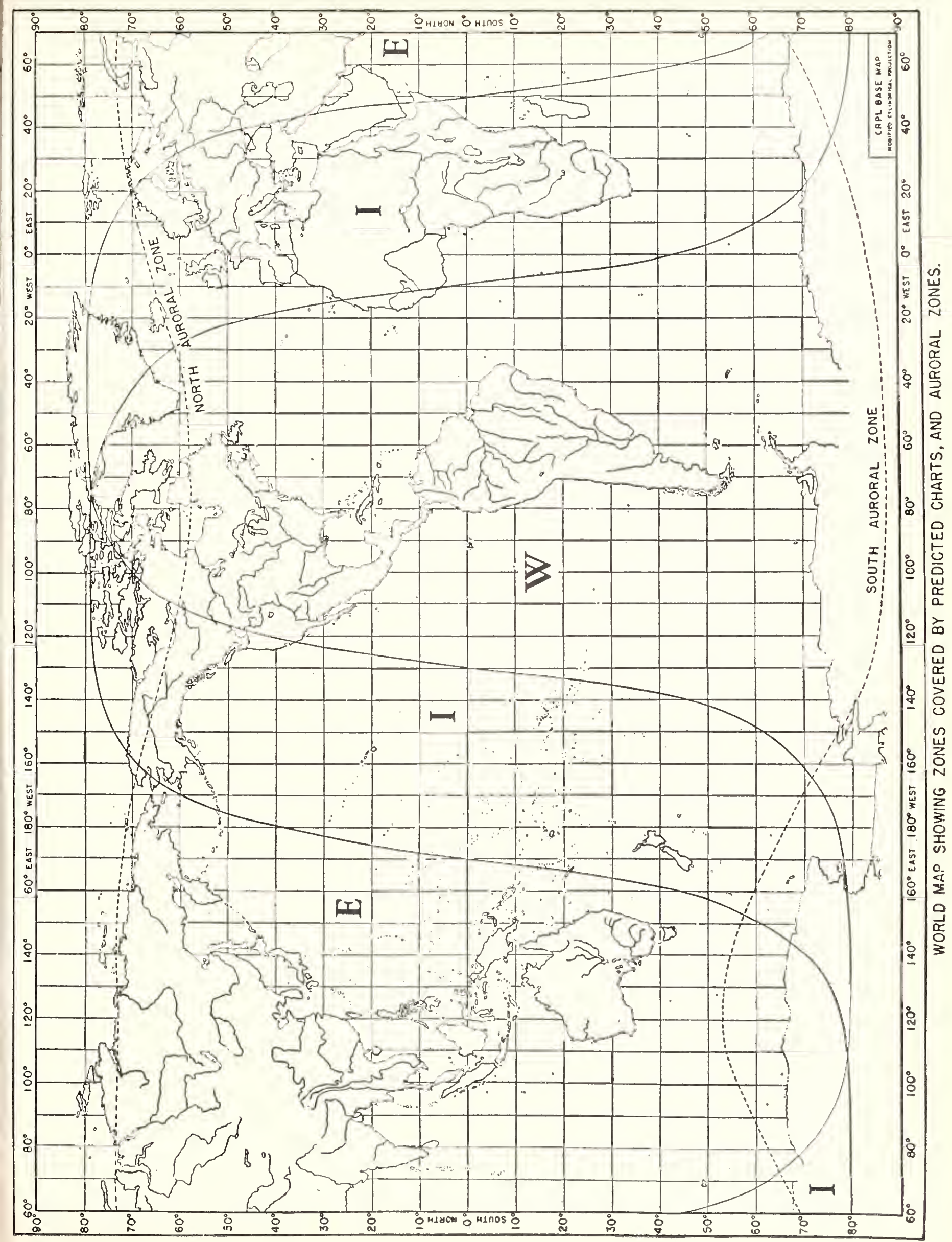




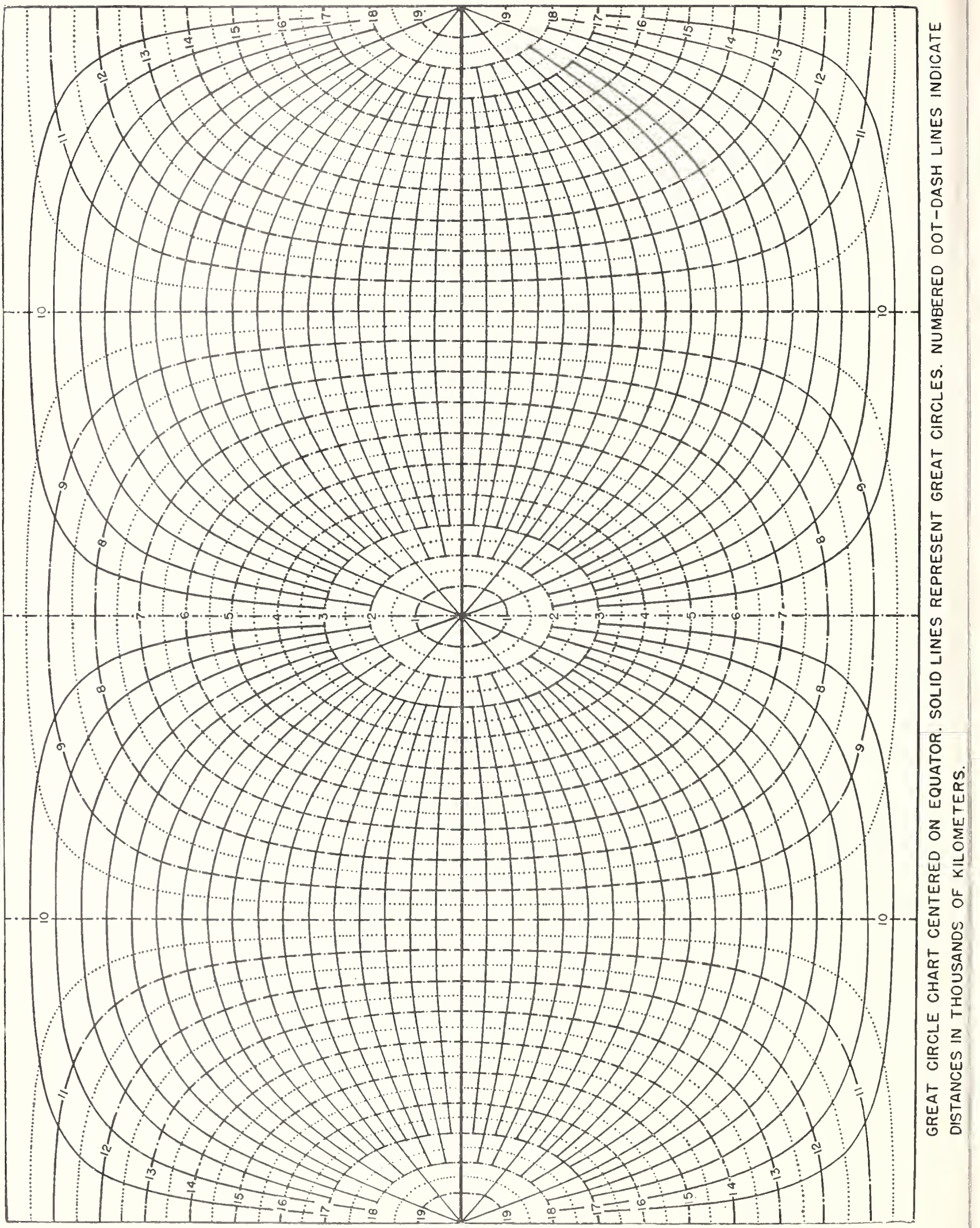




\section{Notes on Use of Predictions}

It is believed that these predictions are reasonably accurate for vertical incidence and for one-hop $F 2$ transmission for average layer height for $4000-\mathrm{km}$ distance over a great circle path. In practice, the picture is often more complicated. The effective antenna-radiated power at low angles of departure may not be sufficient for maximum single hop distance. Also, for a given distance various modes, or conbinations of modes, of propagation are often possible, including combinations of $E$ - and $F$-layer single or multiple hops. Ionospheric forward scatter, backscatter, off-great-circle transmission, and sporadic $E$ may increase the actual MUF for a given circuit over that expected for the simplest great circle mode. Sporadic $E$ may be particularly important during night hours in auroral zones, and during the middle of the day in the summer in temperate zones. Ionospheric layer tilt, horizontal ionization gradients, meteoric or auroral propagation may play an important part.

For many circuits, these may explain why the median MUF may give a better estimate of the FOT than the usual procedure of percentage reduction of the MUF. Use of operating experience in conjunction with these predictions will aid in maintaining the highest possible circuit efficiency.

Reports to this laboratory of discrepancies between predictions and experience are helpful in improving these predictions. Communications should be addressed to Central Radio Propagation Laboratory, National Bureau of Standards, Boulder, Colorado. Please note this is not an address for subscriptions. Subscription information is given elsewhere in this report. 



\author{
UNITED STATES \\ GOVERNMENT PRINTING OFFICE \\ DIVISION OF PUBLIC DOCUMENTS \\ II ASIINGTON 25, D. C. \\ OFFICIAL, BUSINESS
}

PWNALIY FOR PRIVATE USE TO AVOID PAYMENT OF POSTAGE, $\$ 300$ (GPO)

\title{
CRPL Reports
}

[A detailed list of CRPL publications is available from the Central Radio Propagation Laboratory upon request] Duily:

Radio disturbance forecasts, every half hour from broadcast stations WWV and WWVH of the National Bureau of Standards.

Telephoned and telegraphed reports of ionospheric, solar, geomagnetic, and radio propagation data.

Weclily:

CRPL-J. North Atlantic Radio Propagation Forecast.

CRPL-Jp. North Pacific Radio Propagation Forecast.

Semimonthly:

CRPL-Ja. Smimonthly Frequency Revision Factors For CRPL Basic Radio Propagation Predrction Reports.

Monthly:

CRPL-D. Basic Radio Propagation Predictions-Three months in advance. (Dept. of the Army, TB $11-$ 499-, monthly supplements to TM 11-499; Dept. of the Air Force, TO $31-3-28$ series). On sale by Superintendent of Documents. Members of the Armed Forces should address cognizant military office.

CRPL-F. (Part A). Ionospheric Data.

(Part B). Solar-Geophysical Data.

Limited distribution. These publications are in general disseminated only to those individuals or scientific organizations which collaborate in the exchange of ionospheric, solar, geomag netic, or other radio propagation data.

Cataloy of Data:

A catalog of recolds and data on file at the U. S. IGY World Data Center A for Airglow and Ionosphere, Boulder Laboratories, National Bureau of Standards, which includes a fee schedule to cover the cost of supplying copies, is available upon request.

The publications listed above may be obtained without charge from the Central Radio Propagation Laboratory, National Bureau of Standards, Boulder Laboratories, Boulder, Colorado, unless otherwise indicated. Please note that the $F$ series is not generally available.

Cirenlais of the National Bureau of Standards pertaining to Radio Sky Wave Transmission:

NBS Circular 462.

NBS Circular 465.

NBS Circular 5.57

lonospheric Radio Propagation. \$1.25

NBS Circular 582. Worldwide Occurrence of Sporadic E. \$3.25.

Instructions for the Use of Basic Radio Propagation Predictions. 30 cents.

Worldwide Radio Noise Levels Expected in the Frequency Band 10 Kilocycles to 100 megacycles. 30 cents.

These Circulars are on sale by the Superintendent of Documents, U. S. Government Printing Office, Washington 25, D.C. Members of the Armed Forces should adress the respective military office having cognizance of radio wave propagation.

Solected Teclenicul. Notes of the National Bureau of Standards:

Nlis Tech. Note 2.

PB151361. World Maps of F2 Critical Frequencies and Maximum Usable Frequency Factors. $\$ 3.50$ PB151361-2. \$3.53.

Nis Tech. Note 13.

NBS Tech. Note 18 .

PB151372. Technical Considerations Leading to an Optimum Allocation of Radio Frequencies in the Band 25 to 60 He. $\$ 2.50$.

PB151377. Radio Noise Data for the IGY. 50.

18-2. PB151377-2. Quarterly Radio Noise Data (Mar.-May 1959). \$1.00.

18-3. PB151377-3. Q (June-Aug. 1959), \$1.00.

18-4. PB151377-4, etc. (Sept.-Nov. 1959). \$1.50.

NBS Tech. Note 31.

PB151390. An Atlas of Oblique-Incidence Ionograms. \$2.25.

NBS Tech. Note 40-1. PB151399-1. Mean Electron Density Variations of the Quiet Ionosphere, 1: March $1959 . \$ 1.25$.

40-2. I'B151399-2, ete. 2: April 1959. \$1.25

NBS 'Tech. Notr 117. PB161618. Variations in Frequency of Occurrence of Sporadic E, 1949-1959. \$ 0.75 These Technical Notes are on sale by the Office of Technical Services, U. S. Department of Commerce, Washington 25, D. C. Order by PB number. 